\title{
ANNOUNCEMENT
}

\section{A Network on Ethics and Intellectual Disability}

Intellectual disability constitutes one of those fields in healthcare where ethical reflection is sorely needed because of various social and political pressures. In particular the concern for the position of mentally handicapped persons in society calls for serious attention from people who are either engaged in, or committed to healthcare ethics.

The International Network on Ethics and Intellectual Disability is being established to support the effort of such people and enable them to share their interests and concerns in this field with others. The aim of the network is to communicate information on research programs, policy developments, and publications. Its purpose is to stimulate exchange of views and ideas between scientists and ethicists from various religious and philosophical backgrounds and is not committed to any particular school of thought. The network is associated with the International Association of Bioethics. Membership of the network does not include membership of the IAB.

A Newsletter called Ethics and Intellectual Disability will be published twice a year, starting in April 1995. At a later stage the possibility of scientific meetings will be taken into consideration. The network is coordinated by:
Prof. Dr. Johannes S. Reinders
Prof. Dr. Robert M. Veatch
Institute for Ethics
Kennedy Institute of Ethics
Free University
Georgetown University
De Boelelaan 1105, 1081 HV Amsterdam
The Netherlands
Washington, DC 20057
USA

Information on scientific, social, and legal developments regarding mental disability that is relevant to the members of this network can be communicated to RM Veatch at the above address, Phone 202-687-8099/8089, or e-mail VEATCHR@ guvax.georgetown.edu.

In case you are interested in becoming a member of the International Network on Ethics and Intellectual Disability, please contact JS Reinders at the above address, Phone 20-4446605, Fax 20-4446635, or e-mail J.S.Reinders@esau.th.vu.nl. 